\title{
Sistem Informasi Pengarsipan Instrumen Akreditasi Perguruan Tinggi
}

\author{
Bayu Febriadi' ${ }^{1}$ Fana Wiza ${ }^{2}$, Pandu Pratama Putra ${ }^{3}$ \\ 1,2Program Studi Sistem Informasi, Universitas Lancang Kuning \\ ${ }^{3}$ STMIK AMIK Riau \\ e-mail: bayufebriadi9@gmail.com,fanawiza@unilak.ac.id \\ pandupratamaputra91@gmail.com
}

\begin{abstract}
At Lancang Kuning University, there were no facilities that could be used in the preparation of university accreditation instruments, while the need for accreditation data was greatly needed by the academics of the yellowish university in the preparation of accreditation instruments for universities and study programs so that they were still having difficulty filing and presenting form data information, plans strategic and operational and self-evaluation plan along with the documents needed during the visitation activity by the assessor of the National Accreditation Board of Higher Education (BAN-PT). With the use of information technology in the application of computerized based applications for filing and presenting accreditation data needs, it is expected to help the academic community more quickly and precisely in the data processing instrument for accreditation. It is expected that with the development of archiving applications and the presentation of accreditation instruments with the completion of the System Development Lyfe Cycle (SDLC) method in the problem analysis phase, the applications built can improve the quality of accreditation instruments in data processing that are well integrated and can be utilized at any time by the community the Lancang Kuning university.
\end{abstract}

Keywords: Information System, Accreditation, Lancang Kuning University.

\begin{abstract}
Abstrak
Pada Universitas Lancang Kuning belum adanya sarana yang bisa digunakan dalam penyusunan instrumen akreditasi perguruan tinggi sementara kebutuhan data akreditasi sangat dibutuhkan oleh civitas akademika universitas lancang kuning dalam penyusunan instrumen akreditasi perguruan tinggi maupun program studi sehingga masih mengalami kesulitan dalam pengarsipan dan penyajian informasi data borang, rencana strategis dan rencana operasional dan evaluasi diri beserta dokumen-dokumen yang diperlukan saat kegiatan visitasi oleh assessor Badan Akreditasi Nasional Perguruan Tinggi (BAN-PT). Dengan pemanfaatan teknologi informasi dalam penerapan aplikasi berbasis komputerisasi untuk pengarsipan dan penyajian kebutuhan data akreditasi diharapkan dapat membantu civitas akademika lebih cepat dan tepat dalam pengolahan data instrumen akreditasi. Diharapkan dengan adanya pengembangan aplikasi pengarsipan dan penyajian instrument akreditasi dengan penyelesaian metode System Development Lyfe Cycle (SDLC) dalam tahap analisa masalah, aplikasi yang dibangun dapat meningkatkan kualitas dalam pengisian instrumen akreditasi dalam pengolahan data yang terintegrasi dengan baik dan dapat di manfaatkan setiap saat oleh civitas akademika universitas lancang kuning.
\end{abstract}

Kata kunci: Sistem Informasi, Akreditasi, Universitas Lancang Kuning.

\section{PENDAHULUAN}

Sebagian besar dari informasi bisnis saat ini masih dalam format kertas. Bagian ini merupakan bagian perkantoran modern yang tidak berubah[1][2]. Kertas dokumen masih memenuhi laci-laci penyimpan dokumen. Mencari kembali dokumen-dokumen dari tempat penyimpanan ini dapat menjadi 
pengalaman yang melelahkan. Dokumen dapat salah letak atau bahkan hilang. Sangat jarang ada cadangan (back-up) untuk dokumen seperti ini. Pada Universitas Lancang Kuning belum adanya sarana yang bisa digunakan dalam penyusunan instrumen akreditasi perguruan tinggi sementara kebutuhan data akreditasi sangat dibutuhkan oleh civitas akademika universitas lancang kuning dalam penyusunan instrument akreditasi perguruan tinggi maupun program studi sehingga masih mengalami kesulitan dalam pengarsipan dan penyajian informasi data borang, rencana strategis dan rencana operasional dan Evaluasi Diri beserta dokumen-dokumen yang diperlukan saat kegiatan visitasi oleh assessor Badan Akreditasi Nasional Perguruan Tinggi (BAN-PT).

Dengan pemanfaatan teknologi informasi dalam penerapan aplikasi berbasis komputerisasi untuk pengarsipan dan penyajian kebutuhan data akreditasi diharapkan dapat membantu civitas akademika lebih cepat dan tepat dalam pengolahan data instrumen akreditasi [3-6]. Diharapkan dengan adanya pengembangan aplikasi pengarsipan dan penyajian instrument akreditasi dengan penyelesaian metode System Development Lyfe Cycle (SDLC) dalam tahap analisa masalah, aplikasi yang dibangun dapat meningkatkan kualitas dalam pengisian instrument akreditasi dalam pengolahan data yang terintegrasi dengan baik dan dapat di manfaatkan setiap saat oleh civitas akademika universitas lancang kuning.

Berdasarkan uraian diatas penulis mencoba untuk membahas dan menuangkannya dalam sebuah penelitian yang berjudul Sistem Informasi Pengarsipan Instrumen Akreditasi Perguruan Tinggi dimana perumusan dari permasalahan adalah bagaimana merancang dan memanfaatkan sistem informasi pengarsipan sebagai media yang dapat digunakan dalam kebutuhan data instrumen akreditasi pada Universitas Lancang Kuning dalam bentuk informasi yang lebih efektif dan efisien.

\section{METODE PENELITIAN}

Metodologi penelitian dan kerangka kerja penelitian yang digunakan dalam penyelesaian penelitian ini. Kerangka kerja ini merupakan langkahlangkah yang akan dilakukan dalam rangka penyelesaian masalah yang aka dibahas [7]. Adapun tahapan dalam pemodelan yang digunakan adalah pemodelan Waterfall, dan dapat dilihat pada gambar dibawah ini:

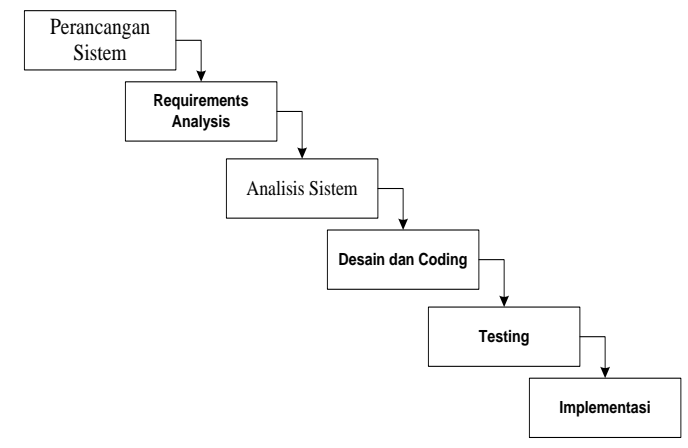

Gambar 1. Tahapan Model Waterfal 
Berdasarkan gambar 1 ada beberapa tahapan dalam membangun sebuah sistem informasi pengarsipan instrumen akreditasi perguruan tinggi yakni: perancangan sistem, requirements analysis, analisis sistem, design systems coding, testing dan implementasi

\section{HASIL DAN PEMBAHASAN}

\subsection{Rancangan sistem informasi pengarsipan instrument akreditasi perguruan tinggi}

Rancangan metode pengembangan sistem development lyfe cycle (SDLC) dengan alat bantu sistem pendekatan unified modelling language (UML) [8$11]$.

\section{a. Usecase Diagram}

Beikut ini Usecase Diagram sistem informasi pengarsipan instrumen akreditasi Perguruan Tinggi di universitas lancang kuning:

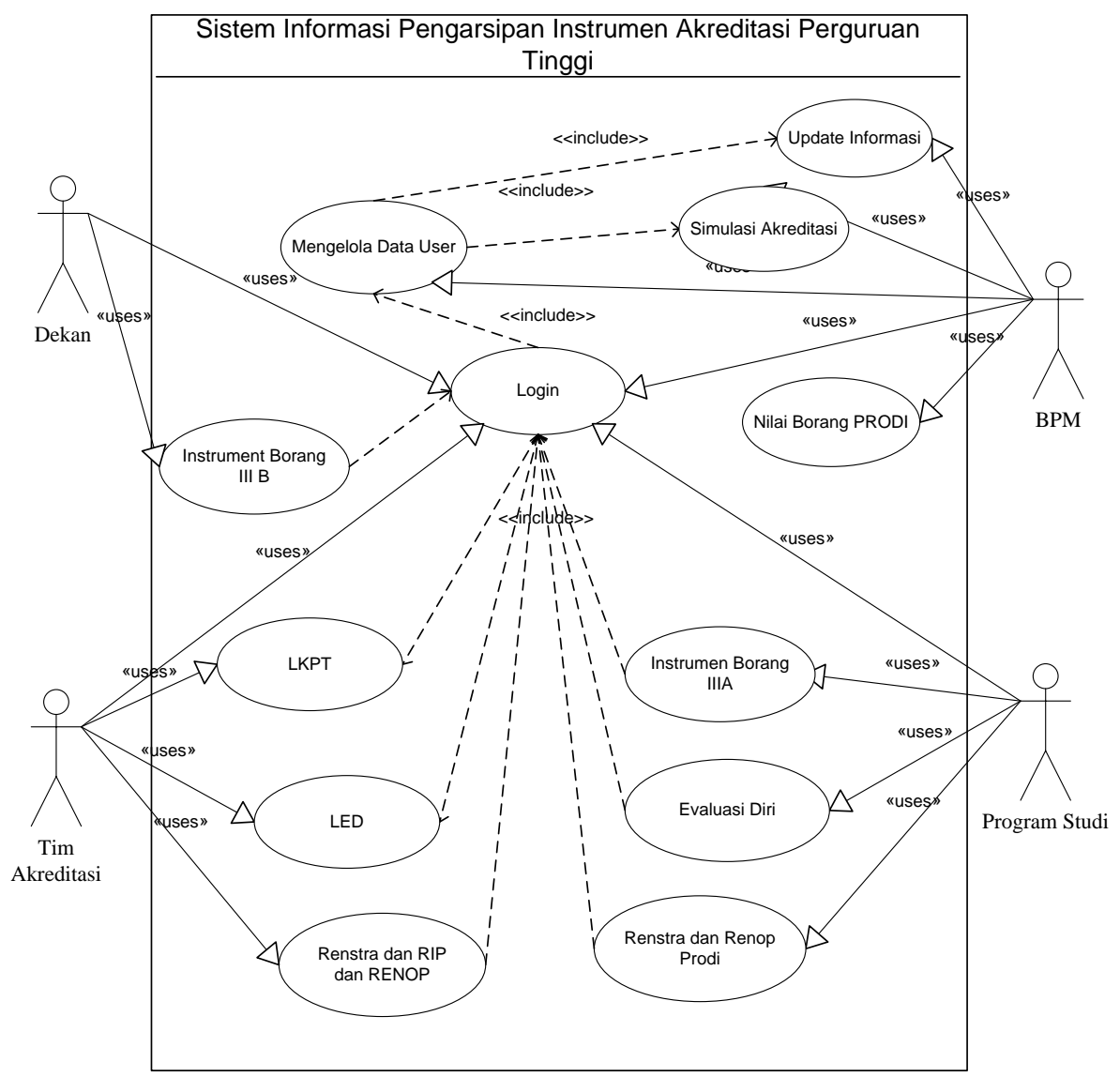

Gambar 2. Usecase Diagram

Penjelasan:

1. Dalam pengembangan sistem ada 4 aktor yaitu : Badan Penjaminan Mutu, Tim Akreditasi, Dekan dan Program Studi.

2. Badan Penjaminan Mutu bertugas mengontrol sistem, mengisi content, mengelola akun pengguna sistem, maintenance aplikasi sistem informasi pengarsipan instrument akreditasi perguruan tinggi. 
3. Tim Akreditasi bertugas sebagai upload Laporan Kinerja Perguruan Tinggi (LKPT), upload Laporan Evaluasi Diri (LED) dan Upload Rencana Strategis (Renstra), RIP dan Rencana Operasional (Renop)

4. Program Studi bertugas sebagai upload instrument borang IIIa, evaluasi diri, Rencana Strategis dan Renop Prodi masing-masing.

5. Dekan bertugas sebagai upload instrument borang IIIb Fakultas.

Semua aktor harus login terlebih dahulu sebelum melakukan kegiatan didalam sistem.

\section{b. Activity Diagram}

Activity Diagram menjelaskan bagaimana alur dari sistem yang dikembangkan dalam register peserta international onference berbasis online, dapat dilihat pada gambar dibawah ini:

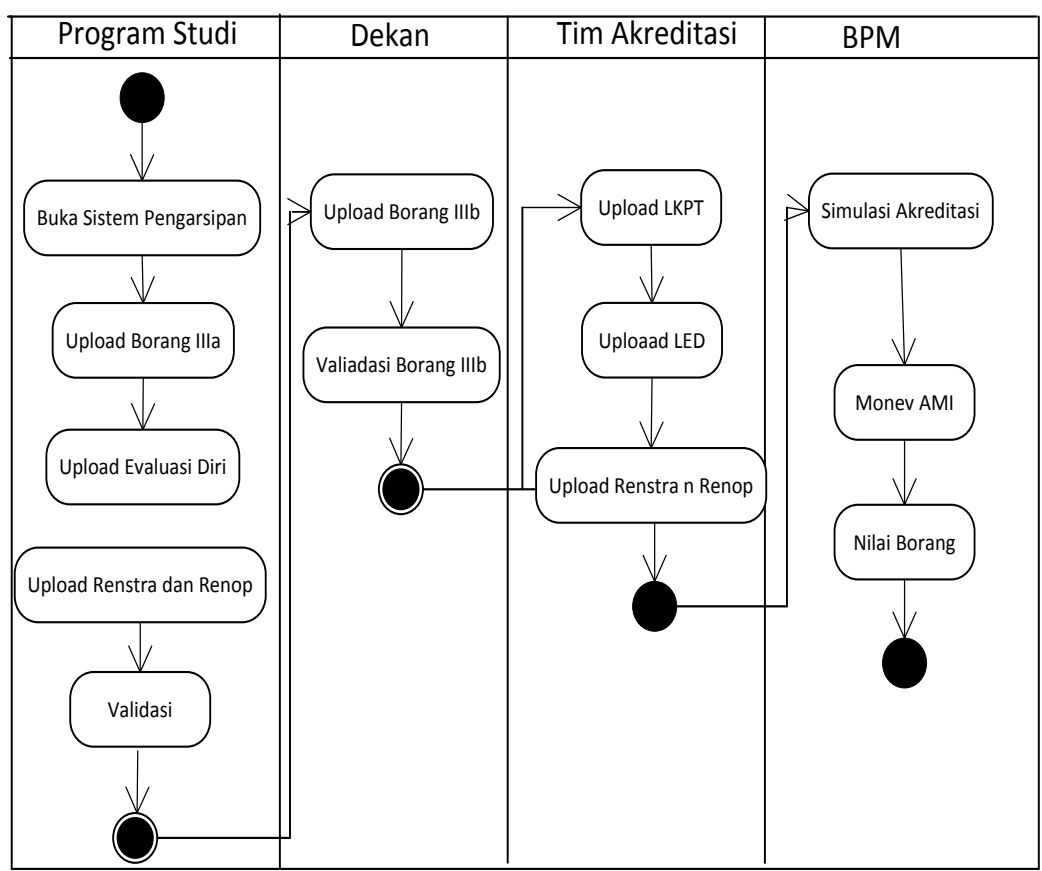

Gambar 3. Activity Diagram

Penjelasan:

1. Pada activity diagram menjelaskan masing- masing actor dalam sistem informasi pengarsipan akreditasi perguruan tinggi universitas lancang kuning sistem yang berbasis online.

2. BPM juga membaca dan melihat panduan dalam melihat instrument akreditasi yang telah diupload oleh program studi dan dekan maupun tim akreditasi lalu melakukan simulasi dalam akreditasi untuk melakukan pemberian nilai akreditasi program studi.

3. Tim Akreditasi menupload data standar laporan kinerja perguruan tinggi dan laporan evaluasi diri maupun renstra dan renop perguruan tinggi.

4. Program Studi mengupload borang dan renstra program studi ke sistem informasi pengarsipan akreditasi perguruan tinggi.

5. Dekan upload boring IIIb Fakultas masing-masing. 


\section{c. Class Diagram}

Class Diagram menjelaskan entitas dan atribut didalam sistem Informasi Sistem pengarsipan instrument akreditasi, dapat dilihat pada gambar di bawah ini:

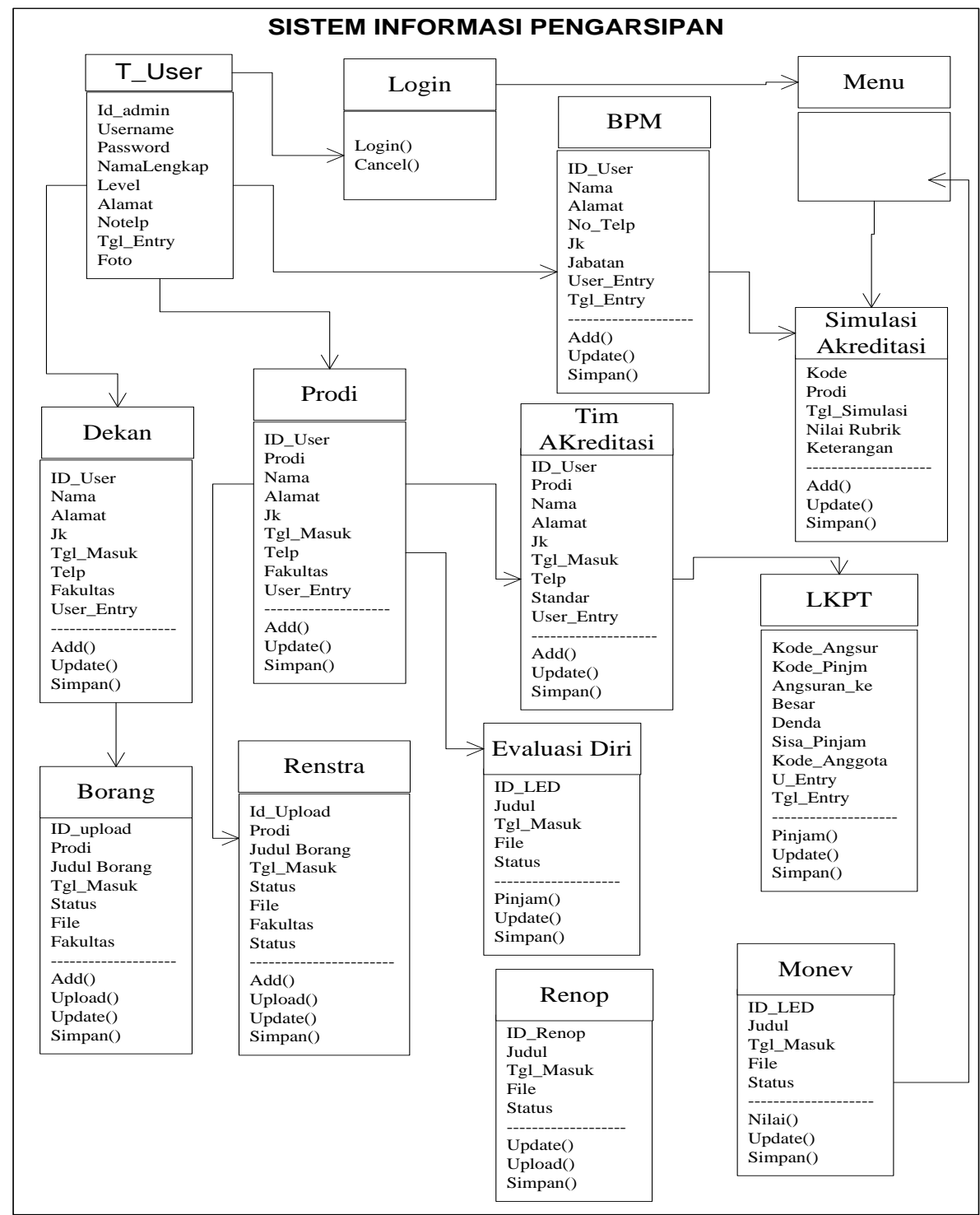

Penjelasan:

\section{Gambar 4. Class Diagram}

Pada class diagram ada 4 entitas dalam sistem Informasi Sistem pengarsipan instrument akreditasi: Login, upload Borang, Upload Evaluasi Diri, Upload Renstra, Upload Renop, Upload LKPT, Tim Akreditasi, BPM, Program Studi dan Dekan.

1. Masing-masing entitas memiliki atribut yang merupakan penjelasan dari entitas tersebut.

2. Pada class diagram juga menjelaskan integritas aliran data dalam sistem yang dikembangkan. 
Jurnal Sains Komputer \& Informatika (J-SAKTI)

Volume 3 Nomor 1 Maret 2019, pp. 152-159

ISSN:2548-9771/EISSN:2549-7200

http://tunasbangsa.ac.id/ejurnal/index.php/jsakti

\subsection{Interface sistem yang baru}

Pada tampilan sitem yang baru yang telah dibangun berdasarkan perancangan sebelumnya dari usecase diagram, activity diagram, dan class diagram. Dari penjelasan Unified Modelling Language.

\section{a. Menu Utama}

Pada rancangam sistem yang dibangun menu utama sistem Informasi Sistem pengarsipan instrument akreditasi pada Universitas Lancang Kuning pada gambar dibawah ini.

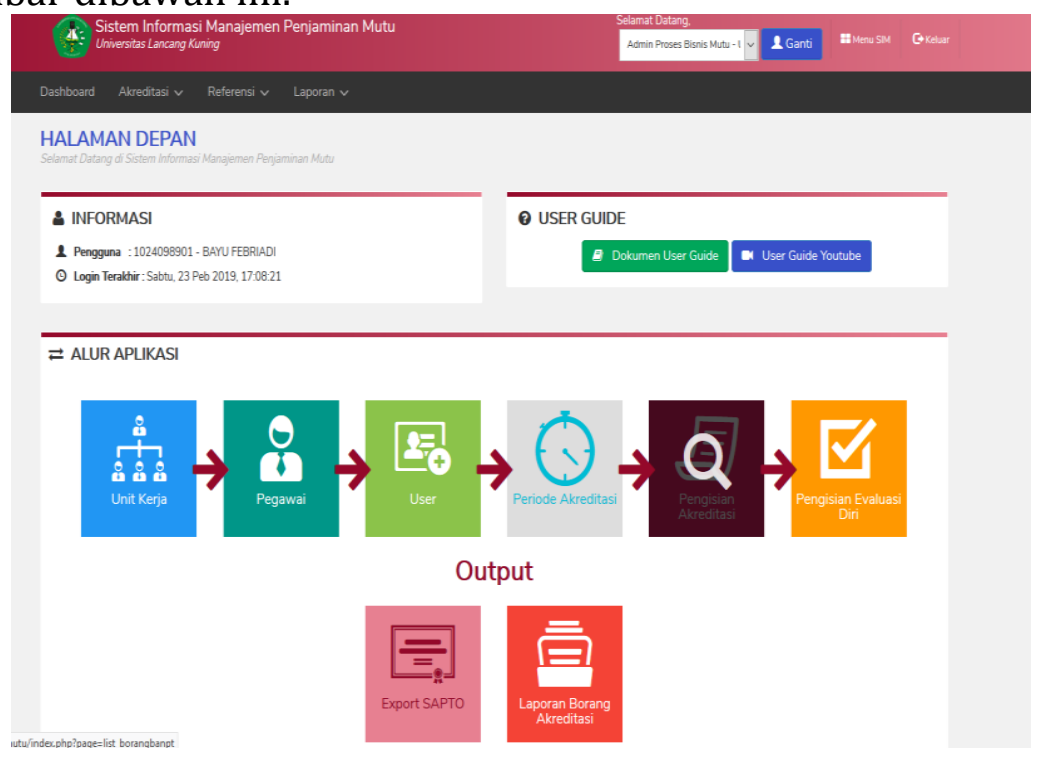

Gambar 5. Tampilan Menu Utama

\section{b. Input Data Borang}

Pada rancangam sistem yang dibangun menu utama sistem Informasi Sistem pengarsipan untuk upload borang instrument akreditasi pada Universitas Lancang Kuning pada gambar dibawah ini.

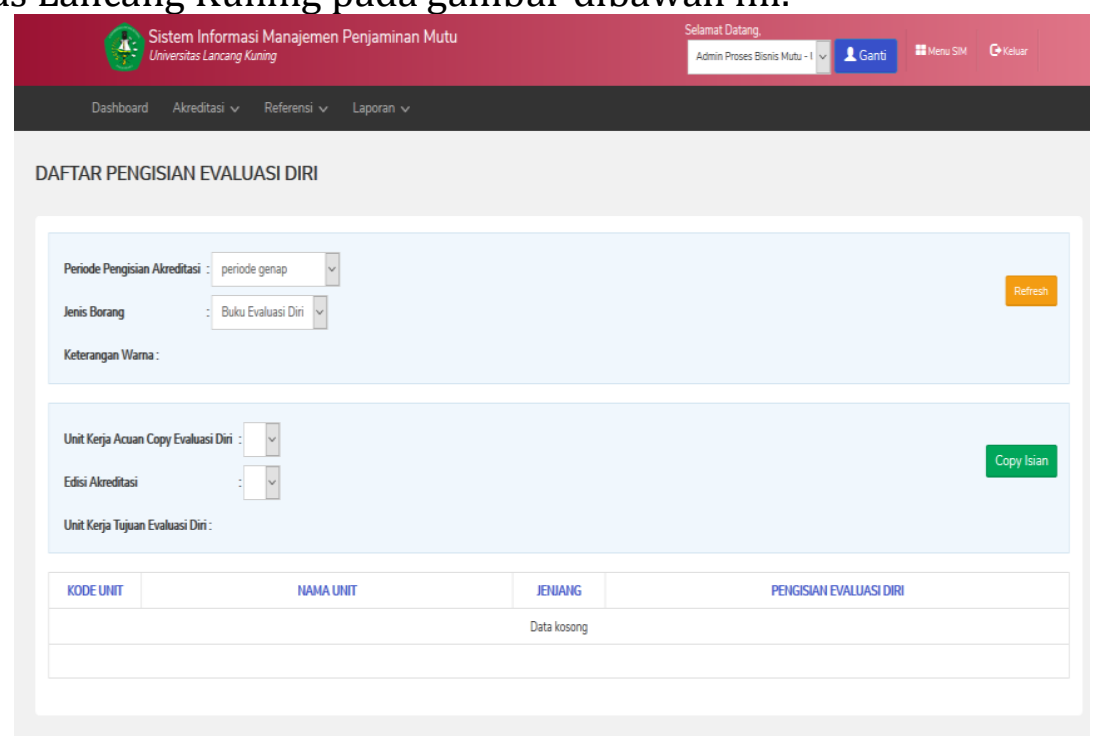

Gambar 6. Tampilan Upload Borang 


\section{c. Daftar Periode Akreditasi}

Pada rancangam sistem yang dibangun menu utama sistem Informasi Sistem pengarsipan untuk upload periode akreditasi pada Universitas Lancang Kuning pada gambar dibawah ini.

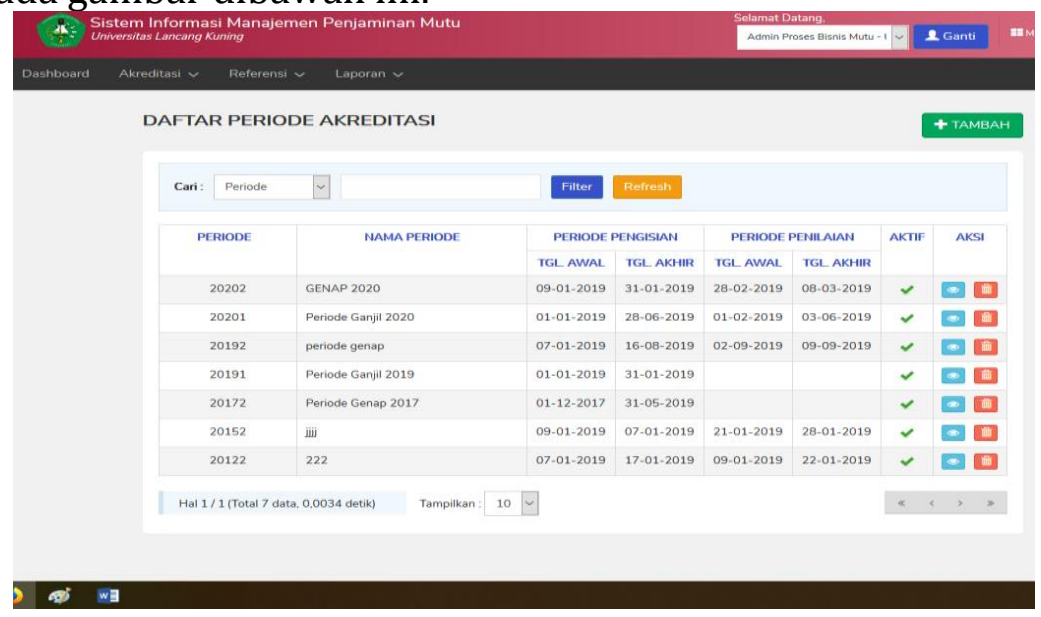

Gambar 7. Tampilan Periode Akreditasi

\section{SIMPULAN}

Setelah dilakukan kegiatan penelitian pada universitas lancang kuning, maka penulis menyimpulkan bahwa:

a. Aplikasi Sistem Informasi pengarsipan instrument akreditasi yang telah dibangun sebagai media dalam kegiatan akreditasi sehingga data instrument akreditasi lebih terintegrasi dengan baik pada Universitas Lancang Kuning.

b. Dengan memanfaatkan aplikasi berbasis data sehingga penogolahan data kegiatan dan pengolahan data boring, renstra, renop, evaluasi diri, LKPT dapat dilakukan dengan cepat dan tepat oleh civitas akademika Universitas Lancang Kuning.

\section{DAFTAR PUSTAKA}

[1] Fathansyah, "Sistem Basis Data. Bandung: Informatika", (2004).

[2] Febriadi, Bayu. 2017. "Efisiensi Sistem Informasi berbasis Online Dalam pengumpulan RPKPS mata Kuliah Untuk Pengembangan Kompeteensi Program Studi" Vol 8, No. 1, Digital Zone, "Jurnal teknologi Informasio dan Komunikasi".

[3] Kadir, Abdul. 2005. Pengenalan Sistem Informasi. Jakarta, Yogyakarta: Andi

[4] Mohammad Yazdi, 2012, e-learning sebagai media pembelajaran interaktif berbasis teknologi informasi, urnal Ilmiah Foristek Vol. 2, No. 1, Maret 2012, Fakultas Matematika dan Ilmu Pengetahuan Alam, Universitas Tadulako.

[5] Herawati, Y., "Rekayasa Perangkat Lunak Untuk Penjualan Perlengkapan Pengantin Adat Minangkabau Berbasis Web", Padang: Institut Teknologi Padang, (2013).

[6] Nyimas Sriwihajriyah, 2012, Perancangan aplikasi E-Profile berbasis online sebagai sarana informasi dosen pada stmik pusri Palembang, Jurnal Sistem Informasi (JSI), VOL. 4, NO. 1, April 2012. 
Jurnal Sains Komputer \& Informatika (J-SAKTI)

Volume 3 Nomor 1 Maret 2019, pp. 152-159

ISSN:2548-9771/EISSN:2549-7200

http://tunasbangsa.ac.id/ejurnal/index.php/jsakti

[7] Nugroho, A., "Rekayasa Perangkat Lunak Berorientasi Objek dengan Metode USDP", Andi, (2010).

[8] Oneto, Erima. 2008. Cascadading Management Style Sebagai media Program Berbasis Web. Bandung: Informatika

[9] Saraswati, E., "Sistem Informasi Akademik Berbasis Web Pada Sekolah Menengah Pertama Negeri 3 Pringkuku", Indonesian Journal On Networking and Security - IJNS, (Volume 2 No 4 - Oktober 2013, ISSN: 2302-5700) .

[10] Simarmata, J, “Rekayasa Perangkat Lunak”, Andi, (2010).

[11] Sutabri, Tata. 2005. Sistem Informasi Managemen. Jakarta: Andi Jogjya 